\title{
Two newly recorded genera Stenodyneriellus and Lissodynerus with three new species from China (Hymenoptera, Vespidae, Eumeninae)
}

\author{
Ting-Jing Li', Bin Chen' \\ I Institute of Entomology \& Molecular Biology, College of Life Sciences, Chongqing Normal University, \\ Chongqing 401331, China \\ Corresponding author: Ting-Jing Li (ltjing1979@hotmail.com)
}

Academic editor: Michael Ohl | Received 11 December 2015 | Accepted 23 March 2016 | Published 28 April 2016

http://zoobank.org/CD2C5D62-D8A0-481B-BC42-5024EBA6A3A7

Citation: Li T-J, Bin Chen B (2016) Two newly recorded genera Stenodyneriellus and Lissodynerus with three new species from China (Hymenoptera, Vespidae, Eumeninae). Journal of Hymenoptera Research 49: 111-127. doi: 10.3897/ JHR.49.7487

\begin{abstract}
These two genera Stenodyneriellus Giordani Soika and Lissodynerus Giordani Soika are newly recorded from China. Three species, namely Stenodyneriellus similiguttulatus sp. n. from Yunnan, S. maolanensis sp. n. from Guizhou, and $S$. depressus sp. n. from Yunnan, are described and illustrated. Stenodyneriellus guttulatus (de Saussure, 1862) and Lissodynerus septemfasciatus feanus (Giordani Soika, 1941) are newly recorded and illustrated from China. A key to the Chinese species of Stenodyneriellus is provided.
\end{abstract}

\section{Keywords}

Hymenoptera, Eumeninae, Stenodyneriellus, Lissodynerus, new record, new species, China

\section{Introduction}

These two genera Stenodyneriellus and Lissodynerus were established by Giordani Soika in 1961 and 1994, respectively. Both of them are Oriental and Australian genera of potter wasps. Some species share the following characters: T2 with a lamella apically, shelf of propodeum developed dorsally, pronotal carina complete and rounded dor- 
sally, T1 slightly narrower than T2. To date, Stenodyneriellus includes 59 species with five subspecies and Lissodynerus contains 17 species with eight subspecies worldwide (Giordani Soika 1961, 1993a, 1993b, 1994, 1995, 1996; Borsato 1994, 2003; Gusenleitner 2007, 2008, 2013; Girish Kumar and Carpenter 2015). Giordani Soika (1994) provided a good basis for further taxonomic study of Stenodyneriellus and Lissodynerus, and hereafter a few new species have been described by Borsato (2003), Gusenleitner $(2007,2008,2013)$, and Girish Kumar and Carpenter (2015). Among the known species of these two genera, not one was reported from China. In our study of the eumenine wasps from China, four species of Stenodyneriellus and one species of Lissodynerus were collected. And as a result of careful comparisons with all known species, three new species of Stenodyneriellus are described and illustrated in detail, and S. guttulatus (de Saussure, 1862) and L. septemfasciatus feanus (Giordani Soika, 1941) are newly reported and illustrated from China. A key to the Chinese species of Stenodyneriellus is provided. The key was produced based on both the examination of specimens and the information extracted from the literature.

\section{Materials and methods}

The specimens examined are deposited in the Institute of Entomology and Molecular Biology, Chongqing Normal University, Chongqing, China (CQNU) and Department of Entomology, College of Plant Protection, Yunnan Agricultural University, Kunming (YNAU). Descriptions and measurements were made under a stereomicroscope (Nikon SMZ1500), and all figures were taken with a stereomicroscope (LEICA EZ4HD) attached to a computer using Leica Application Suite version 2.1.0 software. The ratios used throughout the descriptions were measured in the same magnifying multiple of stereomicroscope. All measurements were taken as the maximal length of body parts measured. Body length was measured from the anterior margin of the head to the posterior margin of metasomal tergum 2. For the density description of punctures, "sparsely" means that interspaces are larger than one puncture diameter, "moderately" means equal to the diameter, and "densely" means less than one diameter. Terminology principally follows Carpenter (1982) and Carpenter and Cumming (1985). The abbreviations used in the text are shown as follows:

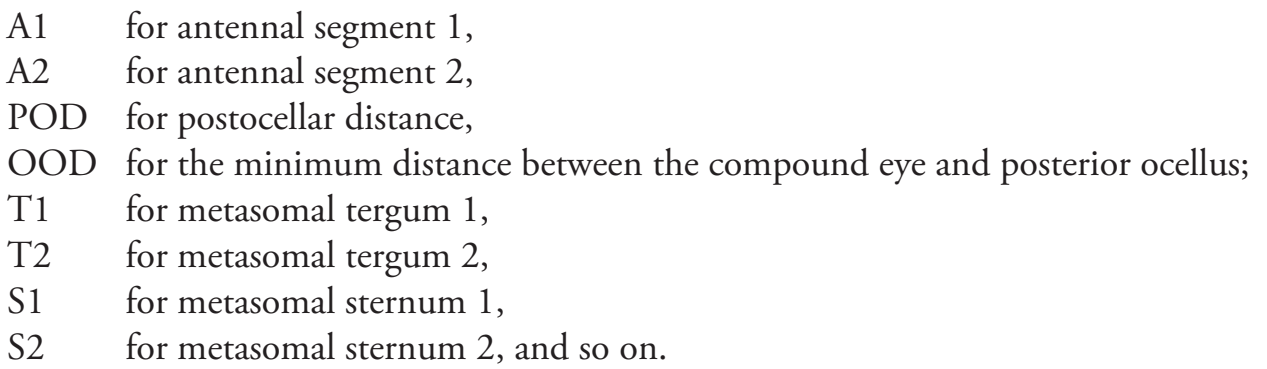




\section{Taxonomy}

\section{Stenodyneriellus Giordani Soika, 1961}

Stenodyneriellus Giordani Soika, 1961: 65, 71; Carpenter 1986: 85; van der Vecht and Carpenter 1990: 55; Giordani Soika 1994: 5, 48-49.

Type species. Stenodyneriellus turneriellus Giordani Soika, 1961, by original designation.

Diagnosis. Clypeus truncated or emarginated apically; length of thorax often slightly longer than its width, but in a few cases almost $2 \times$ its width; metanotum flat or only very weakly and regularly convex; dorsal surface of propodeum almost in the same horizontal plane as metanotum, sometimes more or less prolonged in a medial direction and joined together in the midline separating from the posterior surface of metanotum, shelf on propodeum absent, or well-developed and sometimes protruding upward so as to form two teeth behind metanotum; tegula generally wide and posterior lobe always small and short, but in some species tegula narrow and length nearly $2 \times$ its width; parategula, legs and wings normal; generally, width of T1 approximately $2 \times$ its length and slightly narrower than T2, but in some species T1 obviously narrower than T2, usually T2 without an apical lamella, but in some species with a translucent, thin blade-shaped lamella apically.

Distribution. Oriental and Australian regions.

\section{Stenodyneriellus similiguttulatus sp. $\mathbf{n}$.}

http://zoobank.org/0EB8D6B0-ACBD-40BA-854E-3A148F22CBFA

Figs 1-9

Material examined. Holotype, ${ }_{+}$, China, Yunnan Province, Xishuangbanna State, Jinghong City, Manwai Village, 2201'6.36"N, 100 $50^{\circ} 30.65^{\prime \prime E}, 591-721 \mathrm{~m}$, 30.VII.2003, Qian Jiang, No. 1004061 (CQNU). Paratypes: 1ำ1 ${ }^{\lambda}$, same data as holotype, No. 1004062, 1004063 (YNAU).

Description. Female (Figs 1, 3-4, 6, 8): body length $8.0 \mathrm{~mm}$, forewing length 7.0 $\mathrm{mm}$. Black, with the following parts yellow: clypeus except medial goblet-shaped black spot (Fig. 3), mandible basally, scape ventrally, a large and wide band along inner eye orbit from basis of clypeus to upper frons occupying entire ocular sinus, interantennal spot, a spot on vertex, gena almost entirely, dorsal surface of pronotum anteriorly, a large dorsal spot and a small ventral spot on mesepisternum, tegula anteriorly and posteriorly, parategula, anterior half of scutellum, a large spot on dorsal surface of propodeum apically, a apical band on each of T1-T5 (Fig. 1) and S2, a round spot on the base of T2 laterally, irregular spots on lateral margin of S2 medially and apical margins of S3-S4 laterally (Fig. 8), elongated spots on front and mid femora inside, and all tibiae laterally; antenna except scape ventrally, legs except yellow parts, and tegula medially brown to dark brown. Wings lightly infuscate. Setae pale brown. 
Head. Clypeus medially somewhat convex, with shallow, very thick and minute punctures, apex almost truncated and somewhat emarginated medially (Fig. 3), clypeal width $1.07 \times$ its length, total width: apical width $=1.16: 0.4$, apical width nearly equal to interantennal space; interantennal carina prominent; frons evenly convex and very coarsely punctate, interspaces between punctures with carinae and reticulate; vertex sparsely punctate, cephalic fovea obsolete; POD nearly as wide as OOD.

Mesosoma. Pronotum, mesoscutum, mesepisternum, mesoscutellum and metanotum very coarsely punctate and reticulate, these punctures distinctly deeper than those on frons, punctures on pronotum, mesoscutum and mesoscutellum somewhat sparser than those on mesepisternum and metanotum, and their interspaces with very small and shallow punctures. Pronotal carina complete, rounded dorsally and emarginated laterally; mesoscutum, mesepisternum, mesoscutellum normal; metanotum flat and only apically sloping; propodeum well-developed, dorsal surface almost in the same horizontal plane as metanotum, prolonged in a medial direction protruding upward so as to form two teeth behind metanotum (Fig. 4), well-separated from posterior surface, densely punctate, but obviously sparser and smoother than those on metanotum, interspaces between punctures polished; lateral surface of propodeum punctate and somewhat reticulate, punctures smaller and sparser than mesepisternum; posterior surface widely and deeply concave, smooth and with few punctures. Tegula wide, length slightly longer than its width, and posterior lobe small; parategula hooked and its apex just reaching the apex of tegula.

Metasoma. In dorsal view, T1 domed, its width $1.93 \times$ length and $0.81 \times$ width of T2, without a transverse carina anteriorly, with sparse punctures, punctures distinctly sparser and smaller than those on frons and mesosoma; T2 with a translucent, thin and blade-shaped lamella apically (Fig. 6), punctures on T2 more unobvious than those on T1; S2 widely depressed basally, and with moderate punctures (Fig. 8); visible part of T3-T6 and S3-S6 coriaceous and with minute punctures; the apical yellow bands on T1-T2 obviously wider than those on T3-T5 and with U-shaped gaps medially, the apical yellow band on $\mathrm{S} 2$ interrupted medially.

Male (Figs 2, 5, 7, 9). Body length $7.5 \mathrm{~mm}$, forewing length $8.0 \mathrm{~mm}$. Sculpture, punctuation, setae, and coloration as in female except as follows: yellow spots and bands on the body correspondingly smaller than those in female, clypeus largely black, a surrounding band basally and two spots on the apex laterally yellow (Fig. 5); T2 without a yellow spot laterally; clypeal width $0.97 \times$ its length, total width: apical width = 1.45: 0.6; A13 small, short, and backward only reaching the middle of A11 (Fig. 7); these two teeth on dorsal surface of propodeum sharper than those in female; width of T1 $2.0 \times$ its length and $0.86 \times$ width of T2; genitalia as in Fig. 9, apical tip of penis valve somewhat oblong, volsella wide and blunt apically, and parallel spines elongate without setae; other characters same as those in female.

Remarks. This species resembles $S$. guttulatus (Saussure, 1862) by T2 with a translucent, thin, blade-shaped lamella apically (Fig. 6), and propodeum protruding upward so as to form two teeth behind metanotum dorsally (Fig. 4). It differs from S. guttulatus 


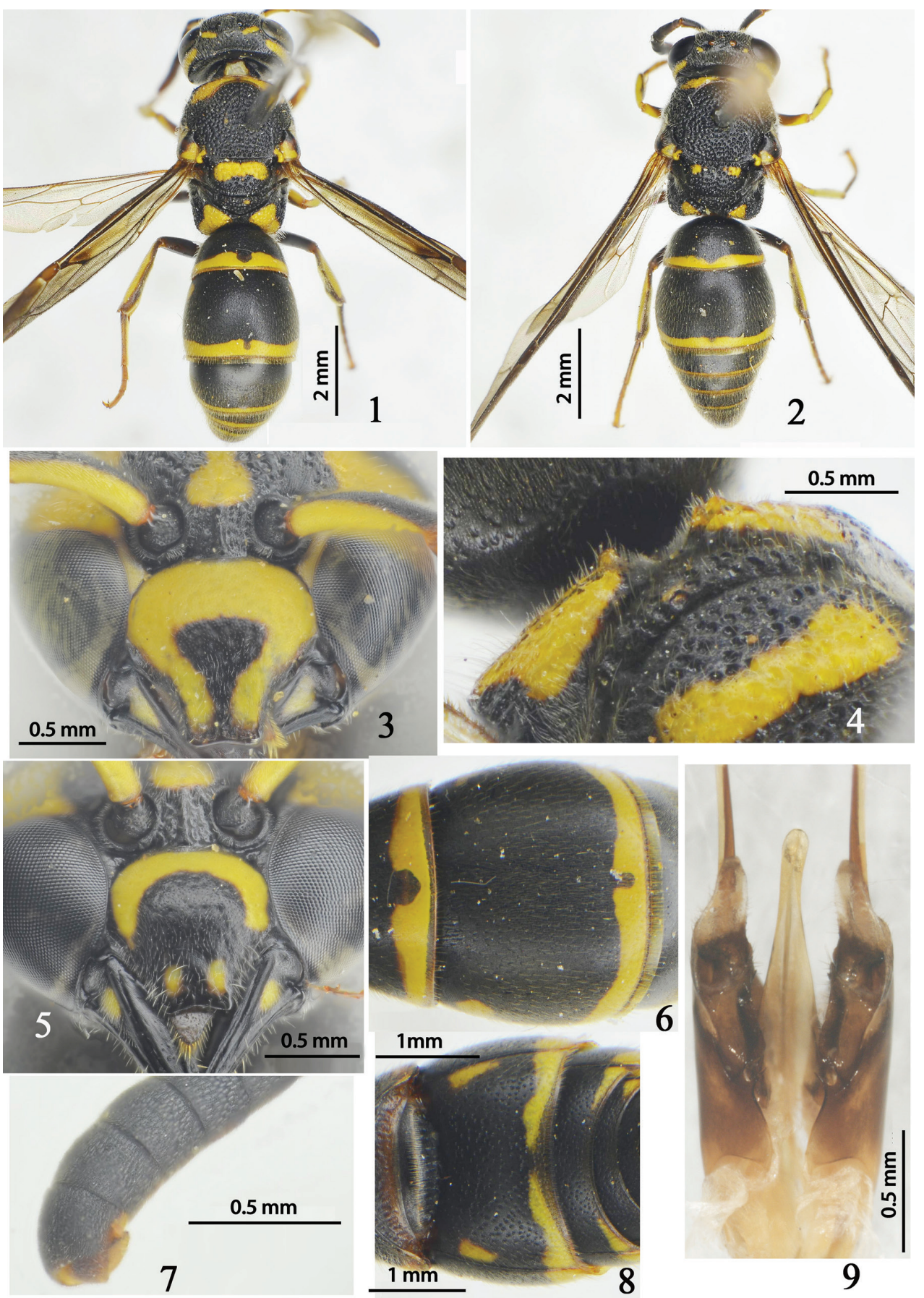

Figures I-9. Stenodyneriellus similiguttulatus sp. n. I habitus of holotype (dorsal view), $q \mathbf{2}$ habitus of

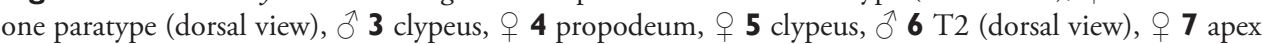
of antenna, $\widehat{O} \mathbf{8}$ S2-S4 (ventral view), $\uparrow \mathbf{9}$ genitalia (front view), $\widehat{\partial}$. 
and all other members of the genus by the following character combination: male A13 reaching the middle of A11 (Fig. 7); female scutum and T1 without yellow spots (Fig. 1); in genitalia, apical tip of penis valve somewhat oblong, and volsella wide and blunt apically (Fig. 9).

Distribution. China (Yunnan).

Etymology. The specific name similiguttulatus is named after the similar species $S$. guttulatus (Saussure, 1862), combined with the Latin word similis (= similar).

\section{Stenodyneriellus maolanensis sp. $\mathbf{n}$.}

http://zoobank.org/3A6E9C87-7746-4F8D-9359-052B88228FFA

Figs $10-14$

Material examined. Holotype, + , China, Guizhou Province, Qiannan State, Libo County, Maolan National Nature Reserve, Dongdai Village, 2514'54.88"N, 10754'4.38"E, 782m, 21.VI.2015, Tingjing Li, No. 1004064 (CQNU).

Description. Female (Figs 10-14): body length $9.0 \mathrm{~mm}$, forewing length $7.5 \mathrm{~mm}$. Black; with the following parts dark ferruginous: pronotum except a thin yellow band medially (Fig. 10), tegula entirely, anterior half of metanotum, and entire dorsal surface of propodeum (Fig. 12); clypeus except medial black spot (Fig. 11), a small spot on mandible basally, scape ventrally, a large and wide band along inner eye orbit occupying entire ocular sinus, interantennal spot, a thin postocular band, a thin band on pronotum medially, parategula, fore tibia laterally, a apical band on each of T1-T3 (Fig. 13), and a lateral spot on apical margin of S2 yellow; fore femur apically, tibia mostly and tarsi dark brown. Wings lightly infuscate. Setae pale brown.

Head. Clypeus somewhat convex medially, coarsely punctate and somewhat reticulate medially, apex deeply emarginated medially (Fig. 11), clypeal width $1.28 \times$ its length, total width: apical width $=1.19: 0.39$, apical width approximately equal to interantennal space; interantennal carina prominent; frons evenly convex, very coarsely and densely punctate, and distinctly reticulate; punctures on vertex more sparsely than those on frons; cephalic fovea present; POD almost as wide as OOD.

Mesosoma. Pronotum, mesoscutum, mesepisternum, mesoscutellum, metanotum and propodeum very coarsely and deeply punctate, and reticulate, these punctures nearly as deep as and sparser than those on frons, punctures on mesepisternum and propodeum denser than those on pronotum, mesoscutum and mesoscutellum. Pronotal carina complete, somewhat rounded dorsally and emarginated laterally; mesoscutum, mesepisternum, mesoscutellum normal; metanotum with a short dorsal convex surface and sloping posteriorly. Propodeum well-developed; dorsal surface almost in the same horizontal plane as metanotum, prolonged in a medial direction protruding upward so as to form two teeth behind metanotum (Fig. 12), well-separated from posterior surface, coarser than lateral and posterior surfaces, and interspaces between punctures distinctly carinate; lateral surface somewhat reticulate; posterior surface widely and deeply concave, and punctate. Tegula wide, length slightly longer than its 


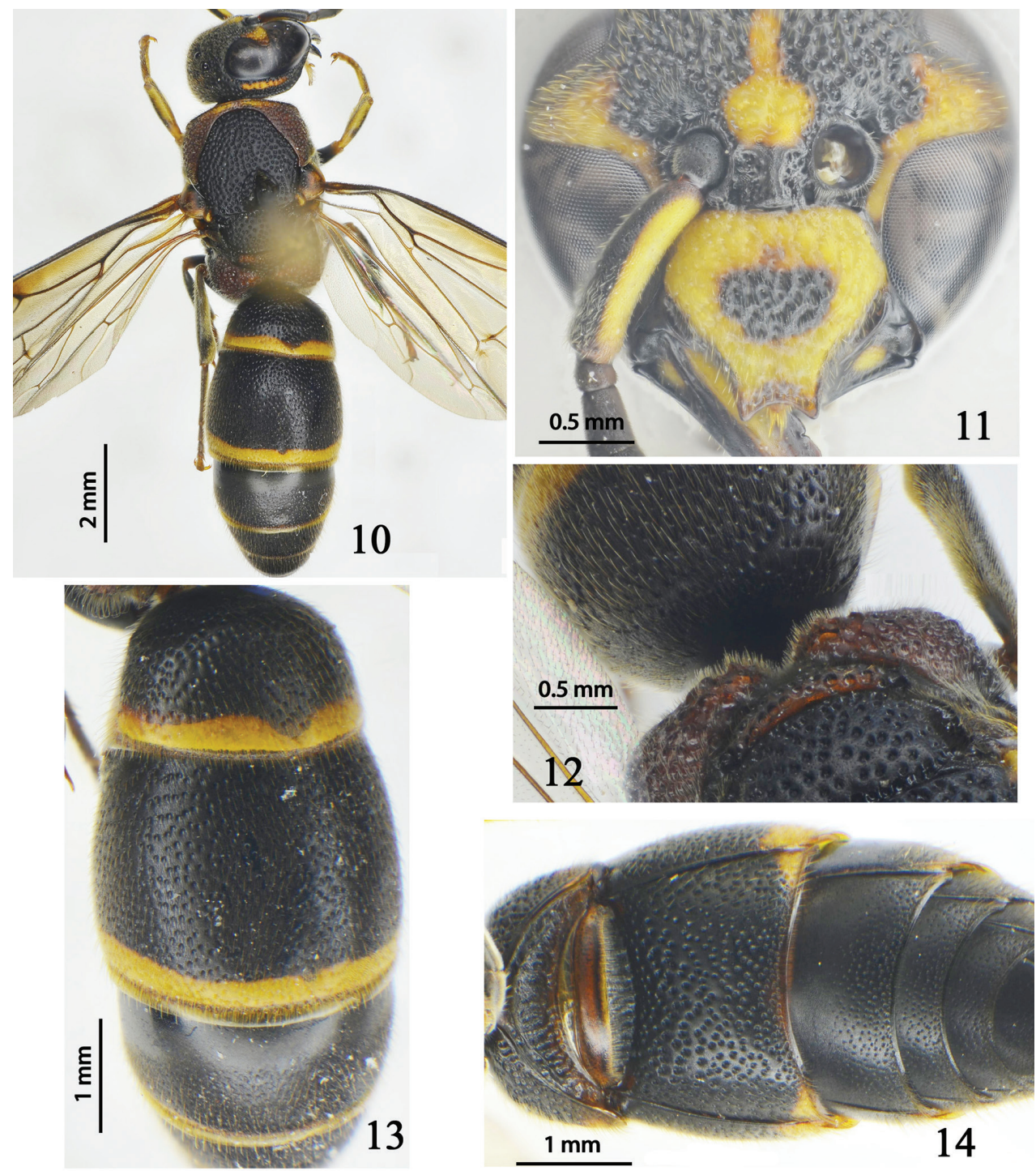

Figures 10-14. Stenodyneriellus maolanensis sp. n. I 0 habitus of holotype (dorsal view), $ᄋ$ I I clypeus, $\bigcirc$ $\mathbf{I} \mathbf{2}$ propodeum, $+\mathbf{I} \mathbf{3}$ metasoma (dorsal view), $\uparrow \mathbf{I} \mathbf{4}$ metasoma (ventral view), + .

width, and posterior lobe small; parategula hooked and its apex slightly exceeding the apex of tegula.

Metasoma. In dorsal view, T1 domed, width $1.81 \times$ its length and $0.83 \times$ width of T2, without a transverse carina anteriorly, distinctly punctate, interspace between punctures almost equal to one diameter, punctures distinctly smaller than those on frons and mesosoma; T2 with a translucent, thin, blade-shaped lamella apically (Fig. 13), punctures similar to those on T1; S2 somewhat depressed basally and distinctly punctate (Fig. 14), punctures distinctly larger and denser than those of T2, and gen- 
erally smaller than those on head and mesosoma; visible parts of T3-T6 and S3-S6 coriaceous and with minute punctures; the apical yellow bands on T1-T2 distinctly wider than that on T3, and with U-shaped gaps medially (Fig. 13).

Male. Unknown.

Distribution. China (Guizhou).

Remarks. This species is easily distinguished from all other species of Stenodyneriellus by the following character combination: $\mathrm{T} 2$ with a translucent, thin, blade-shaped lamella apically (Fig. 13), T2 and S2 distinctly punctate (Fig. 13-14), propodeum protruding upward so as to form two teeth behind metanotum dorsally (Fig. 12), clypeus deeply emarginated apically (Fig. 11), and pronotum, metanotum and dorsal surface of propodeum dark ferruginous.

Etymology. It is named after the type locality of the species, Maolan National Nature Reserve in Guizhou of China.

\section{Stenodyneriellus depressus sp. $\mathbf{n}$.} http://zoobank.org/19308E8E-9A2A-4032-9B94-F731447CDD0C Figs $15-23$

Material examined. Holotype, $\widehat{\partial}$, China, Yunnan Province, Baoshan City, Lujiang Town, Pumanshao, 2501'32.16"N, 98 57'57.20"E, 773m, 17. VII. 2006, Rui Zhang, No. 1004065 (CQNU). Paratypes: 10'; same data as holotype, No. 1004066 (YNAU); 1으, China, Yunnan Province, Xishuangbanna State, Menghai County, Mangao Village, $22^{\circ} 01^{\prime} 10.11^{\prime \prime N}, 100^{\circ} 20^{\prime} 6.96 " E, 716 \mathrm{~m}$, 26. VII. 2011, Xin Zhou, No. 1004067 (CQNU).

Description. Female (Fig 15, 18, 21-23): body length $8.5 \mathrm{~mm}$, forewing length $7.0 \mathrm{~mm}$. Black, with the following parts pale ferruginous (Fig. 15): dorsal surface of pronotum medially, a very small dorsal mesepisternal spot, a transverse band on the basis of scutellum, small spots on dorsal surface of propodeum medially and laterally, and a apical band on each of T1-T2 and S2; the following parts yellow: a wide arcuate band basal-laterally and a apical spot on clypeus laterally (Fig. 18), a spot on mandible basally, scape ventrally, a large and wide band along inner eye orbit from basis of clypeus to upper margin of ocular sinus (not occupying entire ocular sinus), interantennal spot, a long postocular band, tegula outside, parategula, fore and mid femora apically and tibiae laterally, and a spot on apex of mid coxa inside; antenna except scape ventrally and tegula except outside brown. Wings lightly infuscate. Setae pale brown.

Head. Clypeus medially convex, sparsely punctate and interspaces with shallow, very thick and minute punctures, apex moderately emarginated medially (Fig. 18), clypeal width approximately equal to its length, total width: apical width $=1.09: 0.4$, apex wider than interantennal space; interantennal carina prominent; frons evenly convex and very coarsely punctate, interspaces between punctures with carinae and reticulate; vertex very sparsely punctate, cephalic fovea obsolete; POD nearly as wide as OOD. 


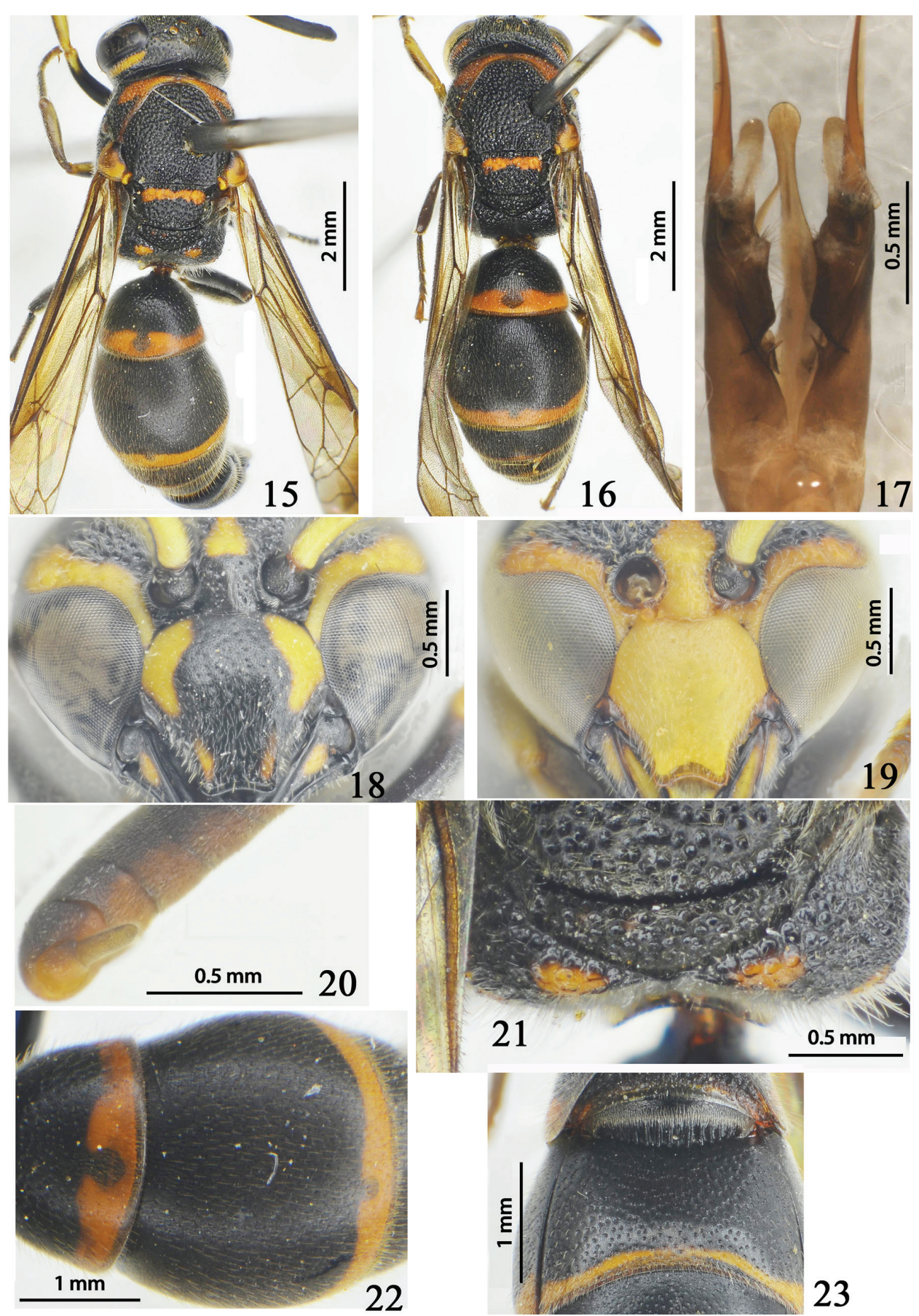

Figures 15-23. Stenodyneriellus depressus sp. n. $\mathbf{5}$ habitus of one paratype (dorsal view), $\subsetneq \mathbf{I} \mathbf{6}$ habitus of

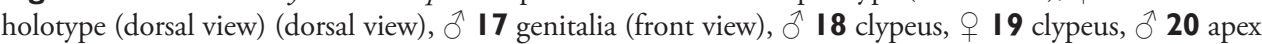
of antenna, $\delta \mathbf{2} \mathbf{l}$ metanotum and propodeum, $+\mathbf{2 2} \mathrm{T} 2$ (dorsal view), $+\mathbf{2 3} \mathrm{S} 2$ (ventral view), + . 
Mesosoma. Pronotum, mesoscutum, mesepisternum, mesoscutellum, metanotum, and dorsal and lateral surfaces of propodeum coarsely and deeply punctate and reticulate, these punctures distinctly deeper than those on frons, punctures on pronotum, mesoscutum, and mesoscutellum sparser than those on mesepisternum, metanotum and propodeum, and their interspaces with very small and shallow punctures. Pronotal carina complete, rounded dorsally and emarginated laterally; mesoscutum, mesepisternum, mesoscutellum normal; metanotum with a very short dorsal convex surface and sloping posteriorly (Fig. 21); dorsal surface of propodeum almost in the same horizontal plane as metanotum, without teeth behind metanotum, interspaces between punctures distinctly carinate (Fig. 21), and well-separated from posterior surface; posterior surface widely and deeply concave, very sparsely punctate and interspaces between punctures smooth. Tegula wide, length slightly longer than its width, and posterior lobe small; parategula hooked and its apex reaching the apex of tegula.

Metasoma. In dorsal view, T1 domed, width $1.47 \times$ its length and $0.80 \times$ width of T2, without a transverse carina anteriorly, sparsely punctate, interspaces between punctures larger than one diameter, punctures distinctly smaller than those on frons and mesosoma; tergum 2 without a lamella (Fig. 22) apically, punctures similar to those on T1; S2 distinctly depressed basally and moderately punctate (Fig. 23), punctures larger and denser than T2, and generally smaller than those on head and mesosoma; visible parts of T3-T6 and S3-S6 coriaceous and with minute punctures; the apical yellow bands on T1-T2 with gaps medially.

Male (Figs 16-17, 19-20). Body length $8.0 \mathrm{~mm}$, forewing length $7.5 \mathrm{~mm}$. Sculpture, punctuation, setae, and coloration as in female except as follows: clypeus entirely yellow (Fig. 19), interantennal spot orange-yellow, spots on mandible and interantennal space larger than those in female, propodeum without spots; clypeal width $0.93 \times$ its length, total width: apical width $=0.95$ : 0.41, apical emargination slightly deeper than that in female ; A13 backward reaching apical margin of A10 (Fig. 20); width of T1 $1.60 \times$ its length and $0.80 \times$ width of T2; genitalia as in Fig. 17, apical tip of penis valve rounded, volsella wide and rounded apically, and parallel spines elongate without setae; other characters same as those in female.

Distribution. China (Yunnan).

Remarks. This species resembles $S$. perpunctatus Giordani Soika, 1994 from Malaysia by T2 without an apical lamella (Fig. 22), dorsal surface of propodeum not protruding upward so as to form two teeth behind metanotum, and propodeum with large dense punctures dorsally, interspaces between punctures carinate (Fig. 21). It differs from $S$. perpunctatus and all other members of the genus by the following character combination: clypeal apex moderately emarginated medially, apical width somewhat wider than interantennal space (Figs 18-19), S2 distinctly depressed basally (Fig. 23), and mesosoma and metasoma with pale ferruginous spots and bands (Fig. 15-16).

Etymology. The specific name is derived from two Latin words: de- and pressus, referring to $\mathrm{S} 2$ of the species being distinctly depressed basally. 


\section{Stenodyneriellus guttulatus (de Saussure, 1862)}

Figs 24-29

Odynerus guttulatus de Saussure, 1862: 200; van der Vecht 1937: 285.

Ancistrocerus megaspilus Cameron, 1907: 85; Giordani Soika 1994: 115.

Odynerus santabongensis Cameron, 1908: 562; Giordani Soika 1994: 115.

Odynerus megaspilus: Dover 1931: 255.

Odynerus guttulatus var. heterospilus van der Vecht, 1937: 286.

Odynerus guttulatus var. nigridorsus van der Vecht, 1937: 287; Giordani Soika 1994 (syn. of S. guttulatus (de Saussure)).

Hylodynerus guttulatus: Gusenleitner 1988: 180.

Stenodyneriellus guttulatus: Giordani Soika 1994: 57, 115; Gusenleitner 2006: 689.

Material examined. $2 \hat{\jmath} 1$, , China, Yunnan Province, Honghe State, Hekou County, southeast Nanxi Town, 21. VII. 2003, Qiang Li and Tingjing Li; 1 9 , China, Yunnan Province, Honghe State, Hekou County, Nanxi Town, 18. VII. 2015, Lin Yang and Lingquan Zeng; 19 , China, Yunnan Province, Honghe State, Hekou County, Nanxi Town, Duoyixia Village 19. VII. 2015, Chunfa Chen; 2 우, China, Yunnan Province, Honghe State, Hekou County, Former Fruit Factory, 12. VII. 2012, Jian Zhu.

Diagnosis. Clypeus truncated apically and almost entirely yellow (Figs 26-27); body with distinct yellow spots and bands (Figs 24-25), propodeum well-developed, prolonged in a medial direction protruding upward so as to form two teeth behind metanotum dorsally; T2 apically with a translucent, thin blade-shaped lamella; male A13 backward and reaching the base of A11 (Fig. 29); genitalia as in Fig. 28, apical tip of penis oblong, volsella narrow and acute apically, and parallel spines elongate without setae.

Distribution. China (new record: Yunnan); India; Thailand; Myanmar; Malaysia; Singapore; Indonesia.

\section{Key to the Chinese species of Stenodyneriellus}

1 T2 without an apical lamella (Fig. 22); dorsal surface of propodeum not protruding upward so as to form two teeth behind metanotum (Fig. 21)

- $\quad$ T2 with a translucent, thin and blade-shaped lamella apically (Figs 6, 13); dorsal surface of propodeum protruding upward so as to form two teeth behind metanotum (Figs 4, 12).

2 Clypeus deeply emarginated apically (Fig. 11); T2 and S2 densely and largely punctate (Figs 13-14); pronotum, metanotum and dorsal surface of propodeum dark ferruginous (Fig. 10) S. maolanensis sp. $\mathbf{n}$.

- $\quad$ Clypeus almost truncated or somewhat emarginated apically (Figs 3, 5, 2627); T2 and S2 more sparsely and thinly punctate (Figs 6, 8); pronotum, metanotum and dorsal surface of propodeum yellow or black 


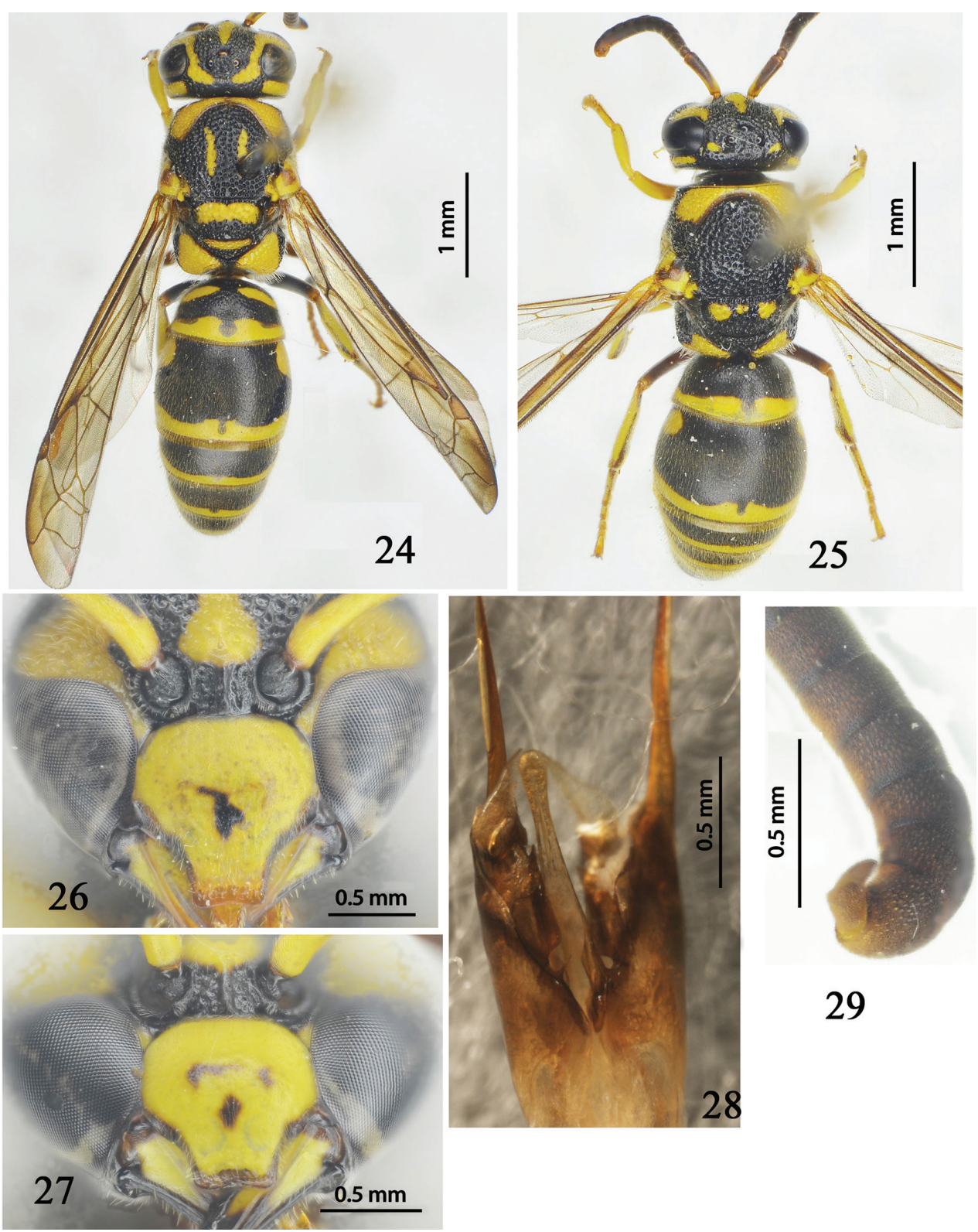

Figures 24-29. Stenodyneriellus guttulatus (de Saussure, 1862). 24 habitus (dorsal view), $\rightarrow 25$ habitus

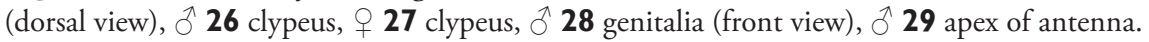

$3 \quad$ Male A13 reaching the basis of A11 (Fig. 29); female scutum with two longitudinal yellow spots and T1 with two large, elongated and transverse yellow spots on anterior face (Fig. 24); in genitalia of male, volsella narrow and acute apically (Fig. 28) 
- $\quad$ Male A13 reaching the middle of A11 (Fig. 7); female scutum and T1 without yellow spots (Fig. 1); in genitalia of male, volsella wide and blunt apically (Fig. 9)

S. similiguttulatus sp. $\mathrm{n}$.

\section{Lissodynerus Giordani Soika, 1993}

Lissodynerus Giordani Soika, 1993a: 135; Girish Kumar and Carpenter 2015: 7664-7667. Lissodynerus Giordani Soika, 1973: 119, used as generic name for Odynerus septemfasciatus var. feanus Giordani Soika, 1941. Unavailable under Article 13.1.1 of the Code.

Trichodynerus Giordani Soika \& Kojima, 1988: 178, used as a generic name in the combination Trichodynerus agilis cursor Giordani Soika \& Kojima, 1988. Unavailable under Article 13.1.1 of the Code.

Type species. Odynerus septemfasciatus Smith, 1857, by original designation.

Diagnosis. Carina of pronotum well-developed, wide rounded, and regularly convex (Fig. 32) dorsally; shelf on the upper propodeum more or less developed, and sometimes confused with big and dense punctures on the interface between dorsal and posterior surfaces, dorsal and posterior surfaces clearly separated, posterior surface entirely concave (Fig. 33); T1 short, width approximately $2 \times$ its length, with an vertical and slightly convex surface anteriorly, interface between anterior and dorsal surfaces with a transverse, smooth, and well-developed carina (Fig. 33); apex on each of T2-T3 or T2-T4 with a brown or black blade-shaped lamella (Fig. 35).

Distribution. Oriental and Australian Regions.

\section{Lissodynerus septemfasciatus feanus (Giordani Soika, 1973), new record} Figs 30-35

Ancistrocerus septemfasciatus var. feanus Giordani Soika, 1941: 239.

Ancistrocerus septemfasciatus feanus: Giordani Soika 1973a: 29.

Lissodynerus septemfasciatus feanus: Giordani Soika 1973b: 119, 1994: 304, 315.

Material examined. $2 q q$, China, Guangxi Zhuang Autonomous Region, Laibin County, Dayao Mountain, 19. VII. 2015, Haixia Zhang and Yuting Hong.

Diagnosis. Female clypeus truncated apically (Fig. 31); vertex with big and moderately dense punctures; shelf of propodeum weak; apex on each of T2-T4 with a black blade-shaped lamella (Fig. 35); mesosoma almost entirely black and only with the following yellow parts: a short band on the anterior surface of pronotum medially (Fig. 32), a tiny spot on metanotum, rarely a spot on top of mesepisternum, and an apical band on dorsal surface of propodeum laterally (Fig. 33); metasoma largely with yellow 


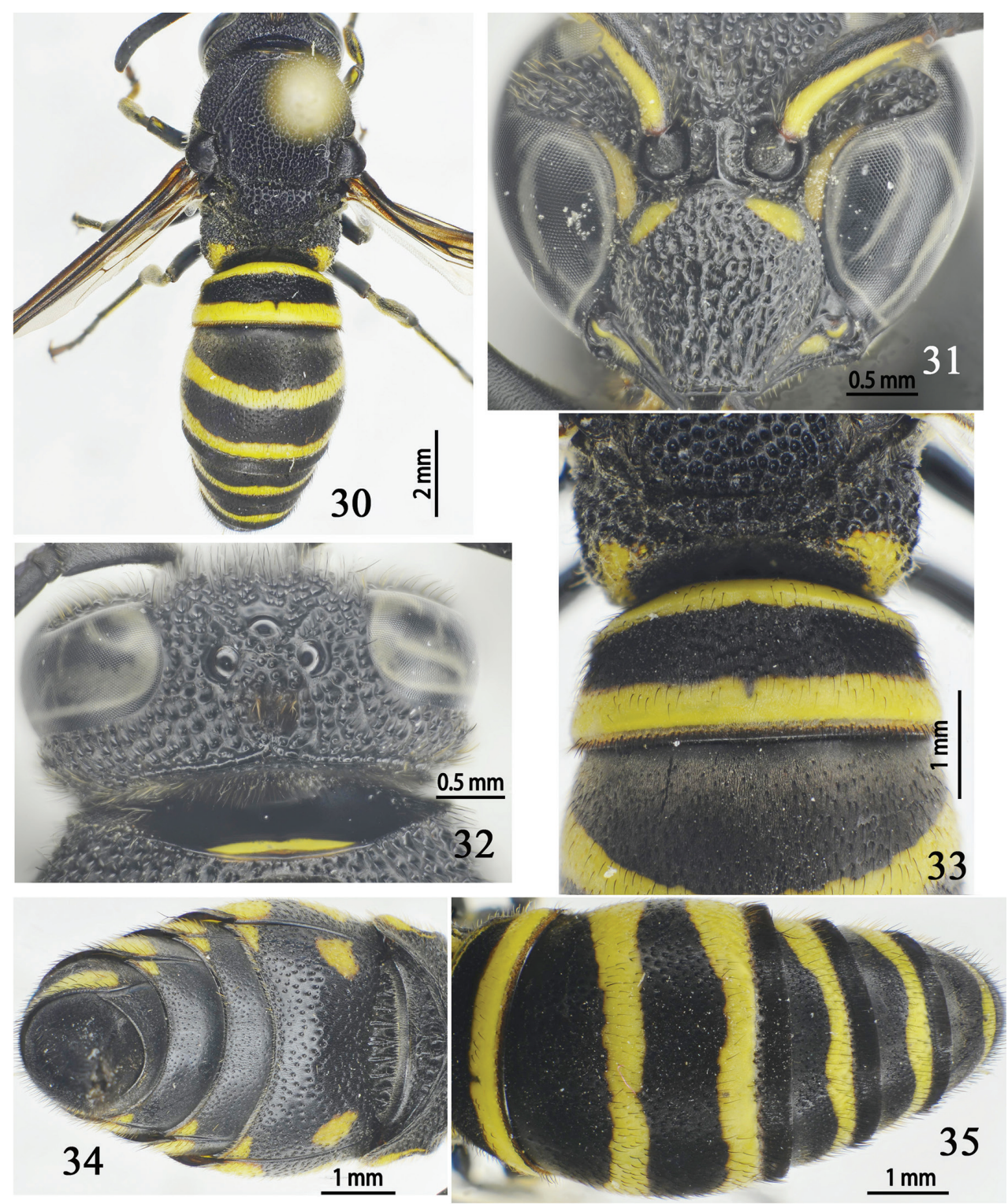

Figures 30-35. Lissodynerus septemfasciatus feanus (Giordani Soika, 1973). 30 habitus (dorsal view), + $\mathbf{3 I}$ clypeus, $+\mathbf{3 2}$ head and pronotum (dorsal view), $\uparrow \mathbf{3 3}$ propodeum and T1 (dorsal view), $q \mathbf{3 4}$ metasoma (ventral view), $\uparrow$ 35. metasoma (dorsal view),

parts (Figs 30, 35): a wide band on the interface between anterior and dorsal surfaces of $\mathrm{T} 1$, a subapical wide band on each of T1-T5, a wide band in the middle of $\mathrm{T} 2$, a spot on the base of S2 laterally, and irregular spots on apical margins of S2-S4 laterally.

Distribution. China (new record: Guangxi); Myanmar; Vietnam; Malaysia. 
Remarks. These female specimens of Lissodynerus septemfasciatus feanus from China are almost same as those from Myanmar, Vietnam and Malaysia (Giordani Soika 1994). Male specimens have not been found yet.

\section{Discussion}

It is well known that species of these two genera Stenodyneriellus and Lissodynerus occur in Australian or Oriental region. In China, southern and southwestern provinces typically belong to the Oriental region, including Guangdong, Guangxi, Hainan, Fujian, Guizhou, Sichuan, Chongqing and Yunnan. It proves that our results are reliable. We also believe that in future, more species or distributions of these two genera may be recorded from the provinces of China belonging to the Oriental region.

\section{Acknowledgements}

We are very grateful to James M. Carpenter (American Museum of Natural History, New York, USA) and Dr. P. Girish Kumar (Hymenoptera Section, Zoological Survey of India, Kolkata, India) for providing copies of many references and their valuable comments; we express our hearty thanks to Prof. Qiang Li (Yunnan Agricultural University, Kunming, China, China) for providing us with the specimens deposited in its Insect Collection under his care. This study was funded by the National Natural Science Foundation of China (Nos: 31372247, 31000976, 31072265), Chongqing Science and Technology Commission (cstc2013jcyjA80015), Young Talent Incubation Programme of Chongqing Normal University (14CSDG07), and the Par-Eu Scholars Program.

\section{References}

Borsato W (1993) Contribution to the knowledge of the eumenids and Australian vespids (Hymenoptera: Eumenidae, Vespidae). Bollettino della Societa Entomologica Italiana 125(3): 245-251.

Borsato W (1994) New or little known Australian Eumenidae (Hymenoptera) (Hymenoptera). ( 2 contribution to the knowledge of Australian vespid). Bollettino della Societa Entomologica Italiana 126(2): 160-170.

Borsato W (2003) Studies on Australian Eumenidae (Hymenoptera: Vespoidea). Museo Regionale di Scienze Naturali Monografie (Turin) 35: 511-565.

Cameron P (1907) A contribution to the knowledge of the Hymenoptera of the oriental region. Annals \& Magazine of Natural History (Series 7) 20: 10-30, 81-92.

Cameron P (1908) On some undescribed Vespidae from Borneo. Deutsche Entomologische Zeitschrift Berlin, Berlin (N.F.) 1908: 561-565. 
Carpenter JM (1982) The phylogenetic relationships and natural classification of the Vespoidea (Hymenoptera). Systematic Entomology 7(1): 11-38. doi: 10.1111/j.1365-3113.1982. tb00124.x

Carpenter JM (1986) A synonymic generic checklist of the Eumeninae (Hymenoptera: Vespidae). Psyche (Cambridge) 93(1-2): 61-90. doi: 10.1155/1986/12489

Carpenter JM, Cumming JM (1985) A character analysis of the North American potter wasps (Hymenoptera: Vespidae: Eumeninae). Journal of Natural History 19(5): 877-916. doi: $10.1080 / 00222938500770551$

Dover C (1931) The Vespidae in the Federated Malay States Museums. Journal of the Federated Malay States Museum, Kuala Lumpur 16: 251-260.

Giordani Soika A (1941) Study on some types of solitary vespids. Bollettino della Societa Veneziana di Storia Naturale e del Museo Civico di Storia Naturale 2(3): 212-273.

Giordani Soika A (1961) Gli Odynerus sensu antiquo del continente australiano e della Tasmania. Bollettino del Museo Civico di Storia Naturale di Venezia 14: 57-202.

Giordani Soika A (1973a) Designation lectotypes and a list of types of Eumenidae, Vespidae and Masaridae described by me in the years 1934-1960. Bollettino del Museo Civico di Storia Naturale di Venezia 24: 7-55.

Giordani Soika A (1973b) Descriptions of some new eumenides. Bollettino del Museo Civico di Storia Naturale di Venezia 24: 97-131.

Giordani Soika A (1976) Contribution to the knowledge of the Australian eumenides (Hymenoptera). Memorie della Societa Entomologica Italiana 55: 109-138.

Giordani Soika A (1993a) Contribution to the knowledge of the eumenides from Australia and New Guinea (Hymenoptera: Vespoidea). Bollettino del Museo Civico di Storia Naturale di Venezia 42: 125-149.

Giordani Soika A (1993b) Noona Dan Expedition 1961-62: Hymenoptera, Eumenidae. Societa Veneziana di Scienze Naturali Lavori 18: 19-24.

Giordani Soika A (1994) A systematic research on some species of eumenides from the Oriental region and Papua. (Hymenoptera: Vespoidea). Annali del Museo Civico di Storia Naturale “Giacomo Doria” 90: 1-348.

Giordani Soika A (1995) New species of eumenides from the Oriental region and Papua. Bollettino del Museo Civico di Storia Naturale di Venezia 44: 91-99.

Giordani Soika A (1996) New or little known Eumenidae from Oriental and Papuan. Bollettino del Museo Civico di Storia Naturale di Venezia 45: 35-45.

Giordani Soika A, Kojima J (1987) Eumeninae wasps collected in Papua New Guinea by J. Kojima (Hymenoptera: Vespidae). Bollettino del Museo Civico di Storia Naturale di Venezia 38: 175-182.

Girish Kumar P, Srinivasan G, Carpenter JM (2015) A new species of Lissodynerus Giordani Soika (Hymenoptera: Vespidae: Eumeninae) from Rutland Island, southern Andaman, India. Journal of Threatened Taxa 7(10): 7664-7667. doi: 10.11609/JoTT.o4022.7664-7

Gusenleitner J (1988) Eumenidae from Thailand, with a key to the Oriental Labus species (Hymenoptera:Vespoidea). Linzer Biologische Beitraege 20(1): 173-198.

Gusenleitner J (1996) Eumenidae of the Oriental region (Hymenoptera: Vespidae). Linzer Biologische Beitraege 28(1): 39-56.

Gusenleitner J (1997) One new Ancistrocerus species from Borneo and change the name of an Oriental eumenides. Linzer Biologische Beitraege 29(1): 95-97.

Gusenleitner J (2006) About collections of Vespidae from India (Hymenoptera: Vespida (Hymenoptera: Vespidae). Linzer Biologische Beitraege 38(1): 677-695. 
Gusenleitner J (2007) Remarkable records of wings folded wasps from Oriental region. Part 3 (Hymenoptera: Vespidae: Polistinae, Eumeninae). Linzer Biologische Beitraege 39(1): 97-104.

Gusenleitner J (2008) Vespidae from the Tanimbar-Islands (Indonesia) in the collection of the Upper Austrian Land Museum. (Hymenoptera: Vespidae: Polistinae, Eumeninae). Linzer Biologische Beitraege 40(1): 765-770.

Gusenleitner J (2013) Notable Vespid-finds from the Oriental Region Part 7 (Hymenoptera: Vespidae: Eumeninae, Polistinae). Linzer Biologische Beitraege 45(1): 121-132.

de Saussure H (1862) Vespid on various Asian and African Museum of Leiden. Stettiner Entomologische Zeitung 23: 129-207.

van der Vecht J (1937) Descriptions and records of oriental and Papuan solitary Vespidae (Hymenoptera). Treubia, Buitenzorg 16: 261-293.

van der Vecht J, Carpenter JM (1990) A catalogue of the genera of the Vespidae (Hymenoptera). Zoologische Verhandelingen (Leiden) 260(15): 1-62. 